\title{
Adaptacão televisiva: uma análise das formas de tratamento pronominais do espanhol madrilenho e bogotano
}

\author{
Adilson Silva
}

\begin{abstract}
Resumo
O presente artigo visa a apresentar alguns dos resultados da pesquisa de iniciação científica (PIBIC-CNPq) titulada "Aquí no hay quien viva: análise contrastiva de uma série espanhola e suas adaptações hispano-americanas" realizada no Departamento de Letras da EFLCH-Unifesp sob orientação da Profa. Dra. Andreia Menezes. Buscamos analisar a versão original espanhola e suas adaptações homônimas produzidas na Argentina (Telefé), no Chile (Chilevisión) e na Colômbia ( $R C N)$ no que tange às questões linguísticas e culturais imbricadas no processo de adaptação. Classificada como uma sitcom, esta série tornou-se um grande fenômeno de audiência da televisão espanhola. Graças ao sucesso televisivo, foi adaptada e transmitida em vários países, como Finlândia, Grécia e Portugal. Não obstante, foi levada também a países de língua espanhola através de adaptação (remake). Neste artigo, tratamos de analisar especificamente o primeiro capítulo da série original espanhola Aqui no bay quien viva (Antena 3, 2003-2006) e de sua versão homônima colombiana (RCN, 2008-2009) no que tange ao uso das formas de tratamento singulares informais, bem como comentar o processo adaptativo a partir dos estudos (sócio)linguísticos e culturais.
\end{abstract}

Palavras-chave: adaptação; sitcom; formas de tratamento; Aqui no bay quien viva; língua espanhola.

\section{Resumen}

El presente artículo tiene por objeto presentar algunos de los resultados de la investigación de iniciación científica (PIBIC-CNPq) titulada "Aquí no hay quien viva: análisis contrastivo de una serie española y sus adaptaciones hispanoamericanas" realizada en el Departamento de Letras de EFLCH-Unifesp bajo orientación de la Profa. Dra. Andreia Menezes. Buscamos analizar la versión original española y sus adaptaciones homónimas producidas en Argentina (Telefé), Chile (Chilevisión) y Colombia $(R C N)$ en lo que se refiere a las cuestiones lingüísticas y culturales 
imbricadas en el proceso de adaptación. La serie se convirtió en un gran fenómeno de audiencia de la televisión española. Gracias al éxito televisivo, se ha adaptado y transmitido en varios países, como Finlandia, Grecia y Portugal. No obstante, fue llevada también a países de habla española a través de adaptación (remake). En este artículo tratamos de analizar específicamente el primer capítulo de la serie original española Aqui no hay quien viva (Antena 3, 2003-2006) y de su versión homónima colombiana (RCN, 2008-2009) en lo que se refiere al uso de las formas de tratamiento singulares informales, así como comentar el proceso adaptativo a partir de los estudios (socio) lingüísticos y culturales.

Palabras clave: adaptación; sitcom; formas de tratamiento; Aquí no hay quien viva; lengua española.

\section{CONSIDERAÇÕES INICIAIS}

Aqui No Hay Quien Viva (doravante ANHQV) é uma série televisiva ficcional de gênero humorístico pertencente à emissora privada espanhola Antena 3 e emitida entre 2002 e 2005, contando com cinco temporadas. Esta série se tornou um dos programas mais exportados da TV espanhola, seja através de emissão (quando a produtora passa a emitir um programa estrangeiro) ou de adaptação (quando se compra o formato de um programa e se produz uma versão local). Nesse sentido, o conceito de "adaptação" é aqui entendido como um processo de modificação de uma obra para que ela possa ser difundida a um público diferente daquele a que seria inicialmente destinado (PUEBLA et al, 2014, p. 20).

A série espanhola foi adaptada a diversos países, como é o caso das versões italiana (Qui non si può vivere), portuguesa (Aqui não bá quem viva), francesa (Faites Comme Chez Vous) e

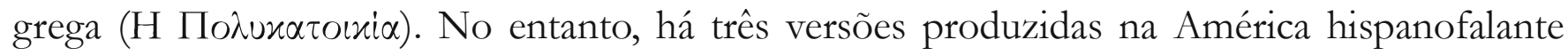
que se diferenciam das outras, uma vez que foram produzidas em países cuja língua oficial também é a espanhola. As adaptações hispano-americanas desse programa foram realizadas em 2008 (versões argentina e colombiana) e 2009 (versão chilena), todas com apenas uma temporada. Chamou-nos a atenção esse movimento de adaptação sobretudo pelo fato de que se criaram versões (remakes) na mesma língua da versão original. Além disso, conforme afirmam Castillo e Rey (2010), as sitcoms se centram nos diálogos, isso é, no conteúdo verbal. Dessa forma, acreditamos que, no processo de adaptação, a questão linguística se torna um fator de destaque, ao lado de outros, como os elementos referentes ao espaço geográfico, vestuário, alimentos etc (COGOLLOS, 2004).

Como afirma Fanjul (2011), a partir da década de 40, os mesmos produtos culturais eram exportados a vários países de língua espanhola. Moreno Fernández (2000, p. 20) relata, no que diz respeito à dublagem, que "No resulta infrecuente que teleseries ya dobladas en un país (por ejemplo, en México) se exhiban tal cual en otros países hispánicos (por ejemplo, en España)".

No entanto, como efeito da globalização, surgiria um outro fenômeno, a glocalização. 
Nas palavras de Robertson (1992, p. 251),

A ideia de glocalização [...] está intimamente relacionada com o que é chamado [...] de micromamarketing: personalização e comercialização de produtos e serviços de base global ou quase-global em escala local e para mercados específicos cada vez mais diferenciados.

Assim, como observa Puebla et alii (op. cit., loc. cit.), a tendência atual é adaptar programas estrangeiros, seja pela dificuldade de criar projetos originais ou pelo sucesso de vendas dos formatos originais. As séries de TV das grandes produtoras e emissoras são criadas visando à exportação e, por isso, apresentam elementos globais, garantindo a reprodução em diversos países (Medina, 2007, p. 74).

À vista disso, e frente à expressiva variação linguística resultante do cotejo entre as versões, este artigo busca comparar as versões colombiana e a original espanhola no tocante à distribuição das formas pronominais, bem como comentar o lugar da variação linguística no processo de adaptação.

Uma vez que $A N H Q V$ é uma sitcom (comédia de situação), cujo gênero é definido pela forte presença de humor e estruturado em diálogos que tendem a representar conversas rápidas, cotidianas, familiares e coloquiais (RODRÍGUEZ, 2011, p. 64), decidimos nos deter à análise dos pronomes de tratamento singular informal, pois seu uso é mais frequente.

\section{Formas de tratamento NA Colômbia E NA Espanha}

Para as linguistas Di Tullio e Malcuori (2012, p. 27), formas de tratamento são pronomes que designam o destinatário do ato de fala, refletindo diferentes relações sociais. Carricaburo, na obra Las fórmulas de tratamiento en el español actual (1997), observa que existem formas de tratamento pronominais e nominais: as formas nominais são caracterizadas pelo uso de substantivos e vocativos e as pronominais, por sua vez, referem-se ao uso dos pronomes pessoais de sujeito. Moreno Fernández (1986, p. 104) trata de expor essa dicotomia:

...los tratamientos nominales [...] suelen estar sujetos, por un lado, a los continuos vaivenes de las modas y movimientos juveniles, por otro, a las peculiaridades de las jergas de todo tipo (profesionales, de barrio, etc.). Los tratamientos pronominales, en cambio, responden a conductas sociales de ámbito más general y, por tanto, su sistematización es subyacente a la mayor parte de los subgrupos sociales, aunque posean diferentes caracteres diatópicos y diastráticos.

Fontanella de Weinberg (op. cit.) apresenta três sistemas pronominais de segunda pessoa empregados nas diferentes regiões linguísticas do mundo hispânico: o primeiro é constituído pelos pronomes tú e usted, já ao segundo pertencem o vos, o tú e o usted, enquanto o terceiro sistema é formado apenas por vos e usted. Ao referir-se à Espanha, a autora (idem, p. 1501- 
1502) afirma que o sistema predominante em todo o país é o primeiro, sendo tú usado como forma de confiança e usted de respeito. Assim, a variante espanhola, no que se refere às formas de tratamento singular, é homogênea. Carricaburo (op. cit., p. 10) sustenta que o tuteo (uso do tú) se impôs sobre o uso de usted, especialmente em áreas urbanas, sendo usado em situações que poderiam ser consideradas de respeito. Em consonância com essa afirmação, o Manual de la nueva gramática de la lengua española (RAE, 2010, p. 322) afirma que o uso do usted vem perdendo espaço no espanhol europeu.

No tocante à Colômbia, Montes (1967, p. 37) afirma, ainda na década de sessenta, que havia um "mosaico de formas y valores que ofrece la segunda persona de singular". O autor afirma (idem), ainda, que o voseo era usado em Bogotá de forma não sistemática. Carricaburo (2004, p. 8), no entanto, afirma que atualmente o voseo está presente apenas na região andina da Colômbia. Já para a Real Academia Española (2005), tanto o voseo quanto o tuteo coexistem em grande parte do país, inclusive na capital, Bogotá.

Carricaburro (op. cit., p. 7) afirma que a Colômbia é um país ustedeante, sugerindo que o ustedeo $^{1}$ se estende por todo o território, sendo mais latente em Bogotá. Moser (2010, p. 286 apud CAMPOS, 2010), ao analisar o ustedeo na Costa Rica, afirma que este pronome adquiriu um sentido polissêmico e se projeta “(...) en un continuum desde situaciones extremadamente informales hasta contextos sumamente formales, es decir, en cualquier situación comunicativa". Kapović (2007. cit., p. 84) sintetiza a situação deste imbróglio linguístico: "El vos en la capital fue sustituído por el usted. Hoy en día, sin embargo, parece que el tú está ganando terreno.".

Em suma, como observa Fontanella de Weinberg (op. cit., p. 1401), o sistema pronominal seria um dos aspectos mais complexos da morfossintaxe espanhola dada a sua ampla variação regional.

\section{Pronomes pessoais em contraste - versão espanhola e colombiana}

Analisaremos o primeiro episódio das duas versões, a original espanhola (2002) e a colombiana (2008). Essa seleção se deveu essencialmente a fatores que podemos chamar de técnicos, pois ambas apresentam maior semelhança quanto à extensão das cenas e às falas dos personagens, além do fato das duas versões estarem ambientalizadas nas capitais, Madri e Bogotá. 
Imagem 1 - versão espanhola ${ }^{2}$

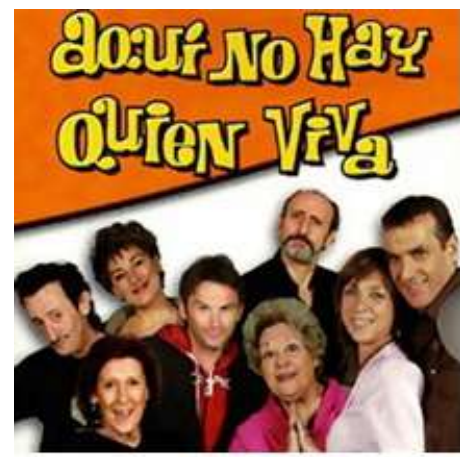

Fonte: Séries Adict - Aquí no hay quien viva
Imagem 2 - versão colombia

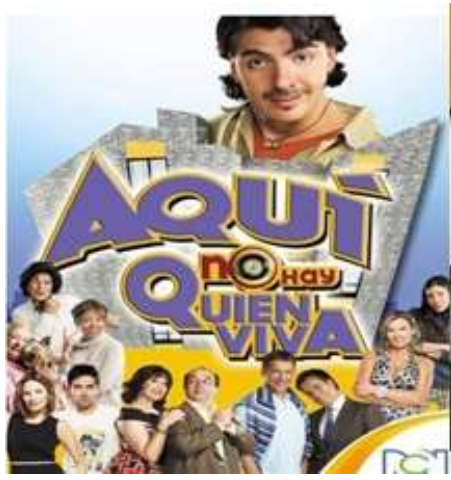

Fonte: Películas en español - Aquí no hay quien viva

As falas foram transcritas do primeiro episódio da série, nominado Érase una mudanza e Érase un trasteo nas versões espanhola e colombiana, respectivamente. O primeiro episódio retrata a chegada de um jovem casal ao edifício. Sua chegada, entretanto, não é pacífica: transforma-se em uma confusão causada pelos vizinhos, extasiados com os novos moradores.

Começamos nosso cotejo com um diálogo entre duas moradoras do edifício:

\begin{tabular}{|c|c|}
\hline Versão Espanhola & Versão Colombiana \\
\hline ¿Y a qué dices que ted & ¿A qué te dedicas? \\
\hline $\begin{array}{l}\text { Lucía: Soy promotora inmobiliaria en el } \\
\text { holding de mi padre. }\end{array}$ & $\begin{array}{l}\text { Carolina: Yo soy promotora inmobiliaria en } \\
\text { el holding de mi papá. }\end{array}$ \\
\hline Paloma: ¡Qué bien! Trabajando con & Yanet: Ah, iqué lindo! Otra vez.... papi \\
\hline papá... & Carolina: Y tú, ¿qué haces? \\
\hline Lucía: Y tú, ¿en qué trabajas? & Yanet: Sí, sí... mi marido se dedica a la \\
\hline $\begin{array}{l}\text { Paloma: Mi marido se dedica a la } \\
\text { enseñanza. Es una eminencia. }\end{array}$ & $\begin{array}{l}\text { enseñanza... es una eminencia gris, te } \\
\text { cuento... }\end{array}$ \\
\hline Lucía: ¿Es catedrático? & Carolina: ¡No puede ser! Entonces, ¿es \\
\hline Paloma: Si, sí.. & catedrático? \\
\hline & $\begin{array}{l}\text { Yanet: Si, sí... él es profesor de español, o } \\
\text { sea, lengua. }\end{array}$ \\
\hline
\end{tabular}

Quadro 1: diálogo entre vizinhas

Na versão original, a personagem Paloma, esposa do síndico, acabara de convidar a récem chegada, Lucía, ao seu apartamento. Embora a veterana moradora seja mais velha, observa-se que Lucía utiliza o pronome "tú" e suas respectivas formas verbais", além disso, é uma relação simétrica, ou seja, ambas utilizam a mesma forma de tratamento. $\mathrm{Na}$ versão colombiana, o diálogo é semelhante e as personagens empregam as mesmas formas linguísticas que as da versão original.

O trecho abaixo retrata o diálogo de um casal que acabara de chegar ao edifício: 


\begin{tabular}{|l|l|}
\hline \multicolumn{1}{|c|}{ Versão Espanhola } & \multicolumn{1}{|c|}{ Versão Colombiana } \\
\hline Roberto: Lucía, ¿te importaría abrir esta & Roberto: Mi amor, ¿tú tienes las llaves? \\
puerta? Es que esto pesa. & Carolina: Robi, se me ha olvidado y el \\
Lucía: Ya sé que pesa, cariño. Pero no & portero quedó entregármelas y yo no lo veo \\
eres el único que va cargado. & por ninguna parte. ¿Tú, sí? \\
Roberto: ¿Y por qué no pruebas con la & Roberto: No, mi amor, yo no lo veo. Timbra \\
llave? & en algún apartamento, mi vida. Estas vainas \\
Lucía: Porque me las tenía que dar el & pesan, neni. \\
conserje. ¿Tú ves al conserje? Pues no & Carolina: Ay, mi amor, no eres el único que \\
hav llaves. & viene cargado. \\
\hline
\end{tabular}

Quadro 2: diálogo entre namorados

Da mesma forma que no diálogo anterior, percebe-se que ambos utilizam a forma verbal "tú" e mantém uma relação linguisticamente simétrica. O mesmo se passa na versão colombiana.

Se até aqui temos diálogos conforme a norma espanhola, os próximos se distanciam dela de diferentes maneiras: nesta seguinte situação, destaca-se o uso da forma verbal correspondente ao pronome "vos" utilizado por Pacho na versão colombiana, em contraposição ao uso do tú na versão original. Pacho/Paco é funcionário da locadora contígua ao condomínio e se apresenta para o porteiro.

\begin{tabular}{|l|l|}
\hline \multicolumn{1}{|c|}{ Versão Espanhola } & \multicolumn{1}{c|}{ Versão Colombiana } \\
\hline Paco: ¿Eres el portero? & Pacho: ¿Sos el portero? \\
\hline
\end{tabular}

Quadro 3: diálogo entre amigos

Embora tenham acabado de se conhecer, em ambas versões os personagens se valem de um pronome informal. Acreditamos que isso se deve por terem idades semelhantes e, também, por pertencerem ao mesmo grupo social.

Analisando outros episódios da versão colombiana, constatamos, porém, que Pacho abandona o voseo e passa a utilizar o usted com o mesmo interlocutor, como podemos perceber nos seguintes trechos: "Wilson, ¿cómo está, amigo mío?” / "Hola, Wilson, nosotros hemos decidido grabar esto junto para usted porque somos amigos"5.

O diálogo abaixo, que retrata a conversa entre duas amigas que dividem o apartamento, também se difere dos dois primeiros diálogos, já que na versão colombiana uma das personagens utiliza o pronome "usted". 


\begin{tabular}{|c|c|}
\hline Versão Espanhola & Versão Colombiana \\
\hline $\begin{array}{l}\text { Alicia: iBuenos dias! Me voy a preparar } \\
\text { algo que tengo un hambre... } \\
\text { Belén: ¿Por qué siempre te levantas de } \\
\text { buen humor? } \\
\text { Alicia: He dormido bien. iEstoy contenta! } \\
\text { Hoy es uno de esos dias que me siento } \\
\text { feliz. }\end{array}$ & $\begin{array}{l}\text { Verónica: ¿Qué día tan lindo! Voy a } \\
\text { preparar algo porque tengo un hambre... } \\
\text { Luz: ¿Qué maldita manía que tiene usted de } \\
\text { levantarse feliz todos los dias! Eso debe ser } \\
\text { como una enfermedad. ¿Por qué no va al } \\
\text { psicólogo? } \\
\text { Verónica: He dormido bien. iEstoy } \\
\text { contenta! Además, hoy es uno de esos días } \\
\text { gue me siento plena y divina. }\end{array}$ \\
\hline
\end{tabular}

Quadro 4: diálogo entre amigas

É certo, neste caso, que o uso deste pronome poderia ser marcado, isto é, o uso do usted é reflexo da situação (a personagem Luz mostra-se aborrecida por sua amiga acordar sempre de bom-humor).

No trecho abaixo, transcrito de um diálogo entre duas irmãs idosas que moram juntas, evidencia-se o uso do usted numa situação informal. Neste caso, no entanto, temos uma relação assimétrica, dado que, enquanto uma das interlocutoras utiliza o usted, a outra lança mão de uma construção com o pronome oblícuo átono “te”, que corresponde ao tú.

\begin{tabular}{|l|l|}
\hline \multicolumn{1}{|c|}{ Versão Espanhola } & \multicolumn{1}{|c|}{ Versão Colombiana } \\
\hline Vicenta: Marisa, Marisa, sal un momento. & Chavita: iFinita, Fina! \\
Marisa: iPero bueno! ¿No ibas tú a la & Finita: Y luego, ¿usted no se habia ido \\
compra? & pa'el supermercado? \\
Vicenta: Estos son nuestros nuevos vecinos & Chavita: Te presento a los vecinos nuevos \\
del tercero. & del cuarto. \\
\hline
\end{tabular}

Quadro 5

Assim como no trecho anterior, o uso do usted poderia estar relacionado à situação. No entanto, como afirma a socióloga argentina Catalina Weinerman (1976), tais mudanças são bem menos frequentes do que costumava ser há séculos atrás. Outra hipótese é a de que o ustedeo e tuteo presentes na versão colombiana poderiam estar concernidos a questões de ordem diastrática, pois os personagens que usam o tú têm maior formação escolar. Nessa perspectiva, há estudos, como o de Olaya (2005), que observam o espanhol bogotano em função da identidade social do emissor. Segundo a linguista (idem), o tuteo predomina nos estratos socioculturais superiores na fala bogotana, mas, na fala popular ${ }^{6}$, é praticamente 
desconhecido, como ressalta Rosselli (2004, p. 12). Contudo, observamos, a partir da análise de outros episódios, que os personagens tendem a alternar as formas de tratamento com os mesmos interlocutores, o que gera, como aponta García Rodríguez (2014, p. 8), problemas de sistematização. Nos parece, ainda, que a configuração histórica e geográfica da cidade tem um papel importante nesse conflito, visto que nesse espaço convergem todas as variedades do país (OLAYA, op. cit., p. 3).

\section{CONSIDERAÇÕES FINAIS}

A diferença entre as duas versões, dentro do que nos propomos a analisar, se encontra no uso das formas de tratamento em situações informais. Não obstante, julgamos que essas diferenças não se sustentariam como um fator motivador para a criação de uma versão local, mas, ligadas a outros de ordem linguística, como a questão lexical e fonética, seriam um contraponto importante e decisivo para uma rede de televisão, uma vez que, como afirma Rodríguez (2011, p. 62) "el hecho de que un producto esté grabado en español no lo iguala en aceptación en toda la comunidad hispanohablante". Os telespectadores tendem a preferir produtos locais e regionais nos quais, além do idioma, podem encontrar outros elementos de identificação (CHAVARRÍA, 1997, p. 2). Nesse sentido, as formas de tratamento podem ser consideradas como um elemento identitário.

A despeito das considerações teóricas dissonantes sobre as formas de tratamento do espanhol bogotano, não só os personagens operam como pontos de referência para milhões de telespectadores que partilham de uma experiência comum e de uma memória coletiva, como defende Thompson (op. cit. p. 219), mas também seus respectivos usos linguísticos.

Como vimos, embora envolva questões linguísticas e culturais, o processo de adaptação é predominantemente comercial, visto que as emissoras de televisão, como afirma o sociólogo britânico John Thompson, "têm por objetivo alcançar a maior audiência possível, pois o tamanho da audiência pode afetar diretamente a valorização econômica dos produtos em questão” (2011, p. 292). Na mesma via, Woodward (2014, p. 18), trabalhando com a questão da identidade, assevera que "Os anúncios só serão eficazes no seu objetivo de nos vender coisas se tiverem apelo para os consumidores e se fornecerem imagens com as quais eles possam se identificar".

Para obter êxito nessa empreitada, modifica-se, como tratamos de explanar neste trabalho, alguns elementos linguísticos. Para Thompson (op. cit, p. 290), essas e outras técnicas são “...mecanismos institucionalizados que possibilitam reduzir a indeterminação que brota da ruptura entre produção e recepção, e fazem isso de uma maneira que coadune com os objetivos gerais das instituições interessadas". A questão linguística não seria, portanto, a causa única de se fazer uma adaptação, mas, sim, uma consequência desse complexo processo. 
No entanto, é importante não perdermos de vista que se trata do gênero sitcom, no qual a cor local, que é construída principalmente pela língua, é de extrema importância. Dessa forma, o que encontramos nessa adaptação vai de encontro à prática do uso do chamado "espanhol neutro/internacional", uma vez que pode estar relacionado mais fortemente ao fenômeno da glocalização. 


\section{NotAs}

1. Ao uso do usted como forma de confiança/informalidade dá-se o nome de ustedeo.

2. Disponível em <http://seriesadicto.com/serie/aqui-no-hay-quien-viva $>$. Acesso em 24/maio/2016.

3. Disponível em <http://seriesadicto.com/serie/aqui-no-hav-quien-viva $>$. Acesso em 24/maio/2016.

4. No espanhol, a tendência é o não preenchimento dos pronomes pessoais de sujeito, assim sendo, se levará em consideração neste artigo as formas pronominais - quando aparecem - e também suas respectivas formas verbais.

5. Trechos extraídos respectivamente dos episódios "Érase un desgobierno" e "Érase un descubrimiento".

6. O termo habla popular alude ao socioleto popular, o qual, segundo o autor, é usado pelos estratos inferiores da escala social de Bogotá. 
CARRICABURO, N. Las fórmulas de tratamiento en el español actual. Madri: Arco libros, 1997.

CASTILLO, G. P.; REY, P. R. "La sitcom o comedia de situación: orígenes, evolución y nuevas prácticas". In: Fonseca, Journal of Communication. Salamanca, v. 1, p. 188-218. jan. 2010. Disponível em: $<$ http://revistas.usal.es/index.php/21729077/article/view/11875 >. Acesso em: 30 abr. 2015.

COGOLlOS, E. C. "Mecanismos de construcción de la identidad cultural en las series de ficción: El caso de la televisión autonómica en España". In: Estudios sobre las Culturas Contemporáneas, Colima, v. 10, n. 20, p. 45-77. 2004. Disponível em: $<$ http://www.redalyc.org/articulo.oa?id $=316$ 02003>. Acesso em: 30 abr. 2015.

CHAVARRÍA, M. P. "Variables dialectales del español: ¿Valor agregado o descuento cultural en el flujo de productos audiovisuales?". In: Razón y palabra, ISSN-e 1605-4806, No. 7, 1997

DI TULLIO, A. \& MALCUORI, M. (2012). Gramática del español para maestros y profesores del Uruguay. Montevideo, ANEP. ProLEE.

FANJUL, A. "Policêntrico e Pan-hispânico. Deslocamentos na vida política da língua espanhola". In: Xoán, BAGNO; M. (orgs.). Políticas da norma e conflitos linguísticos. São Paulo: Parábola, 2011. p. 299-332.

FERNÁNDEZ, M. "Sociolingüística de los tratamientos. Estudio sobre una comunidad rural". In: Anuario de Letras, XXIV (1986), pp. 87-120.

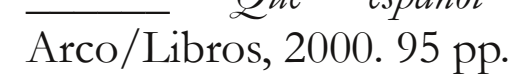

FONTANELLA DE WEINBERG, María Beatriz. 1999. "Sistemas pronominales de tratamiento usados en el mundo hispánico". Gramática Descriptiva de la lengua española. Ed. I. Bosque y V. Demonte. Madrid: Espasa-Calpe. 1401-25.

GARCIA, R. A. (2014). Las fórmulas del tratamiento en el español colombiano. Seminario "Lingüística variacional: el uso de la lengua española en el mundo". Universität Viadrina Frankfurt Oder (Alemania)

KAPOVIĆ, MARKO (2007): "Fórmulas de tratamiento en dialectos de español: fenómenos de voseo y ustedeo." Hieronymus, 1, 65-87. Zadar: Sveučilišste u Zadru. Disponível em: <https://www.google.com/url? q=http://www.unizd.hr/portals/16/casopis/Marko Kapovic Voseo v ustedeo.pd-

f\&sa $=$ D\&ust $=1484581096580000$ \&us$\mathrm{g}=$ AFQjCNE6gPBEGuokq9bWoc3IS7H6bs nQKQ.> Acesso em: 20/05/2016. MEDINA, M. (2007). "Explotación económica de las series familiares de televisión". Em: Communication \& Society, v. 20, $\mathrm{n}^{\circ}$ 1, p. 51-85. Disponível em: < http://www.unav.es/fcom/communication-society/es/articulo.php?art id=50.> Acesso em: 30/04/2015.

MONTES, J. J. (1967): "Sobre el voseo en Colombia", TbBICC XXII, págs. 94-100.

PUEBLA MARTÍNEZ. B., et. al, (2014). Remakes a la española. El proceso de adaptación de series extranjeras en España. Em: Vivat Academia, p. 19-42. Disponível em $<\underline{\text { ht- }}$ tp://www.vivatacademia.net/index.php/vivat/article/view/564. $>$ Acesso em: 16/08/2015. 
RAE (2010). Manual de la nueva gramática de la lengua española. Madrid: Espasa.

ROBERTSON, R. Globalização: teoria social e cultura global. São Paulo: Vozes, 1992.

RODRÍGUEZ, P. L. "Español de españa y español de Ameria en el doblaje: La variación lingüística a través de um estudio de caso". In: Sáez, Daniel; Braga, Jorge et all. Últimas tendencias en traducción e interpretación. Iberoamericana,
THOMPSON, J. B. Ideologia e Cultura Moderna: teoria social crítica na era dos meios de comunicasãa de massa. Tradução do Grupo de Estudos do Instituto de Psicologia da PUCRS. Petrópolis: Vozes, 2012.

WEINERMAN, C. Sociolingüistica de la forma pronominal. México: Editorial Trillas, 1976.

WOODWARD, K. "Identidade e diferença: uma introdução teórica". In: SILVA, Tomaz Tadeu da. (Org.). Identidade e diferença: a perspectiva dos Estudos Culturais. $14^{\mathrm{a}}$ ed. Petrópolis/RJ: Vozes, 2014. 